\title{
SATB family chromatin organizers as master regulators of tumor progression
}

\author{
Rutika Naik ${ }^{1}$ Sanjeev Galande (D)
}

Received: 4 June 2018 / Revised: 30 August 2018 / Accepted: 2 September 2018 / Published online: 9 November 2018

(c) Springer Nature Limited 2018

\begin{abstract}
SATB (Special AT-rich binding protein) family proteins have emerged as key regulators that integrate higher-order chromatin organization with the regulation of gene expression. Studies over the past decade have elucidated the specific roles of SATB1 and SATB2, two closely related members of this family, in cancer progression. SATB family chromatin organizers play diverse and important roles in regulating the dynamic equilibrium of apoptosis, cell invasion, metastasis, proliferation, angiogenesis, and immune modulation. This review highlights cellular and molecular events governed by SATB1 influencing the structural organization of chromatin and interacting with several co-activators and co-repressors of transcription towards tumor progression. SATB1 expression across tumor cell types generates cellular and molecular heterogeneity culminating in tumor relapse and metastasis. SATB1 exhibits dynamic expression within intratumoral cell types regulated by the tumor microenvironment, which culminates towards tumor progression. Recent studies suggested that cell-specific expression of SATB1 across tumor recruited dendritic cells (DC), cytotoxic T lymphocytes (CTL), T regulatory cells (Tregs) and tumor epithelial cells along with tumor microenvironment act as primary determinants of tumor progression and tumor inflammation. In contrast, SATB2 is differentially expressed in an array of cancer types and is involved in tumorigenesis. Survival analysis for patients across an array of cancer types correlated with expression of SATB family chromatin organizers suggested tissue-specific expression of SATB1 and SATB2 contributing to disease prognosis. In this context, it is pertinent to understand molecular players, cellular pathways, genetic and epigenetic mechanisms governed by cell types within tumors regulated by SATB proteins. We propose that patient survival analysis based on the expression profile of SATB chromatin organizers would facilitate their unequivocal establishment as prognostic markers and therapeutic targets for cancer therapy.
\end{abstract}

\section{Introduction}

A plethora of studies involving molecular and genomic studies from the last decade revealed that tumors exhibit complex and tissue-specific gene regulatory mechanisms controlled by a multitude of transcription factors binding to enhancers or promoters, thereby orchestrating expression of a specific set of genes. Regulation of gene expression occurs through alteration in chromatin accessibility via recruitment of nucleosome-remodeling complexes, histone-

Sanjeev Galande

sanjeev@iiserpune.ac.in

1 Centre of Excellence in Epigenetics, Department of Biology, Indian Institute of Science Education and Research, Pune 411008, India modifying enzymes [1-4] and chromatin organizers that coordinately regulate multiple genes via modulation of higher-order chromatin architecture [5-14].

SATB (Special AT-rich binding protein) family proteins have emerged as key regulators that integrate higher-order chromatin organization with the regulation of gene expression [15-21]. Recent studies have demonstrated that both SATB1 and SATB2 are instrumental in cancer progression [17, 19, 22-26]. Both members of the SATB family chromatin organizers are involved in long-range enhancer function [27-29] extension of chromatin modifications $[29,30]$ and dynamic tethering of chromatin loops $[15,31,32]$.

Post-translational modifications of SATB1 act as dynamic molecular switches regulating the expression of a large number of genes during T cell activation [33]. SATB2 was identified as a protein belonging to the SATB chromatin organizer family and implicated in transcriptional 
control and chromatin remodeling [34]. Last decade has witnessed elucidation of roles of SATB1 in an array of biological phenomena including $\mathrm{X}$ chromosome inactivation [35], T cell development [36, 37] and differentiation [38-40], anti-tumor immunity [41], autoimmune diseases [42-44], Wnt signaling [38], hematopoiesis [45, 46] and neuronal development [47-49]. SATB2, a relatively less characterized homolog of SATB1, is known as a versatile regulator functioning in the differentiation of multiple cell types including embryonic stem cells, osteoblasts and immunocytes [20]. SATB2 is expressed in erythroid cells and activates $\gamma$-globin genes by binding to their promoters and recruiting the histone acetyltransferase PCAF [50]. SATB2 plays key roles in craniofacial patterning, osteoblast differentiation, cortical neuron differentiation and skeletal development [51-53]. Collectively, this affirms the role of higher-order chromatin organization and gene regulation mediated by SATB chromatin organizers towards governing diverse cellular functions.

Number of studies in the past decade have demonstrated strong association between expression of SATB1 with tumor aggressiveness in an array of cancer types including colorectal [54], breast [55], pancreatic [56], nasopharyngeal [57], bladder [58], prostate [59, 60], lung [61], ovarian [62], liver [63], glioma [64], lymphoma [35], cutaneous $\mathrm{T}$ cell lymphoma [65, 66], endometrial carcinoma [67] and kidney [68]. These studies suggest SATB1 as an ideal therapeutic target for cancer therapy; however, there are few contradictory reports in case of breast and colorectal cancer [6971]. With respect to SATB2, its expression is correlated with aggressiveness of colorectal [72], bone [73], head and neck cancer [74] demonstrating its cancer specific role.

This review highlights the role of SATB1 towards tumor progression, metastasis, regulation switch between pluripotency and cellular differentiation and immunemodulatory functions. Current review uniquely delineates the importance of the cell-specific expression of SATB1 across tumor recruited dendritic cells (DC), cytotoxic $\mathrm{T}$ lymphocytes (CTL), T regulatory cells (Tregs) and tumor epithelial cells along with tumor microenvironment. This dynamic expression pattern of SATB1-upregulation in Tregs and DCs while downregulation in CTLs along with crosstalk of tumor niche leads to tumor progression and inflammation. Furthermore, comprehensive analysis of correlation of expression of the two members of SATB family chromatin organizers with patient survival for an array of tumor types clearly revealed their tissue-specific regulation. These correlations strongly suggest that status of expression of both SATB1 and SATB2 may serve as a highly reliable prognostic marker. Current review highlights the importance of balance between the expression of SATB chromatin organizers along with intratumoral cellular and molecular functions governed. We propose that the combined expression pattern of SATB1 and SATB2 provides improved insights towards understanding tumor progression and therefore establish them as reliable prognostic markers.

\section{Molecular mechanisms of regulation of SATB chromatin organizers in cancer}

Chromatin organizer proteins provide a structural network to regulate an array of genes, dysregulation of which could exert detrimental effects on the cellular phenotype. This presumably provides mechanistic clues towards how the aberrant expression of chromatin organizers might lead to accumulation of molecular events culminating in tumorigenesis. SATB1 regulates distant genes by selectively tethering specialized regions of the genome resulting in the formation of a characteristic 'cage-like' network [15, 29]. SATB1 provides a nuclear architectural platform that facilitates anchoring of an array of genes mediated via its interaction with specific genomic sequences [32, 75, 76]. SATB1 binds to the genomic regions outside heterochromatin, precisely at the base of chromatin loop domains suggesting its role in the positioning of genes in regions of the nucleus where their expression can be modulated [15] In this manner SATB1 mediates expression of multiple genes which could be coordinately regulated, thereby enabling cells to alter their function in response to signals.

Chromosomes are organized into chromosome territories, largely separated from each other in the cell nucleus [77]. It has been proposed that chromatin, in chromosome territories, is folded into small-scale chromatin loops of $\sim 50-200 \mathrm{~Kb}$ [78]. A recent report confirmed the existence of the chromosomal scaffold, loop organization and characterized the pathway of mitotic chromosome formation. This elegant study revealed that mitotic chromosomes fold as compact arrays of chromatin loops. During prophase, the interphase organization is rapidly lost in a condensindependent manner and arrays of consecutive $60 \mathrm{~Kb}$ loops are formed. Further, during prometaphase, $\sim 80 \mathrm{~Kb}$ inner loops are nested within $\sim 400 \mathrm{~Kb}$ outer loops [79]. The accessibility of chromatin modifiers along with chromatin domain architecture and spatial arrangement within the nucleus are determinants of gene expression [6, 80-82]. Chromatin is organized into a non-random 3D topology that is very essential for the establishment of the regulatory network for gene expression [76, 78, 83, 84]. Biological and biophysical principles governing the three-dimensional folding of chromatin are central to the understanding of epigenetic regulation during adaptive responses and in complex diseases, such as cancer [85]. Interestingly, in this context SATB1 is postulated to enhance transcription by 
promoting the formation of small chromatin loops locally between regulatory elements, which would reduce the physical volume of within the gene cluster.

Global alterations in nuclear architecture and chromatin folding conspire with unstable epigenetic states of the primary chromatin fiber to drive the phenotypic plasticity of cancer cells [85]. Apart from the cellular transformation in cancer, it is established that SATB1 modulates the epigenetic and transcriptional pathways required for hematopoietic stem cell division, self-renewal, and lymphoid potential [86]. SATB1 acts as a 'docking site' for several chromatin modifiers including ACF, ISWI, and HDAC1 [28, 33] suggesting a molecular mechanism governing cellular plasticity. SATB1 recruits histone modifying enzyme p300 on promoters of tumor oncogenes and maintains histone activation mark such as histone H3K9/14 acetylation mark culminating in breast cancer progression. In contrast, SATB 1 recruits HDAC1 on promoters of tumor suppressor genes, depletes the activation marks and thereby reducing their expression $[18,87]$. SATB1 is speculated to affect histone modification states at the SATB1 binding sites and also at nearby genes [17, 88]. This presumably explains the dynamic molecular regulation mediated by SATB chromatin organizers towards tumor progression.

Multiple studies over the past decade have provided strong evidence implicating chromatin remodeling and regulatory elements in cancers. Chromatin remodeling machinery such as the SWItch/Sucrose Non-Fermenting (SWI/SNF) complex, also referred to as the BRG1Associated Factor complex have been implicated in cancers $[89,90]$ wherein the core subunit SNF5 of the SWI/ SNF complex acts as a tumor suppressor [91]. Cancers are associated with a specific alteration of the SWI/SNF subunit, which acts either as tumor suppressor genes or as oncogenes, and therefore constitute diagnostic or prognostic biomarkers [92]. Thus, dysregulation of epigenetic regulatory network presumably provides malignant cells an adaptive and selective advantage to escape homeostatic regulation [93-95].

SATB family chromatin organizers mediate higherorder chromatin organization thereby regulating gene expression [15, 27, 53]. Precisely, SATB1 might play role in specifying the nuclear location of specific genes thereby mediating other aspects of transcriptional control such as chromatin remodeling and access to transcription activators or repressors, to orchestrate gene expression $[15,29]$. Depending on its interaction partners, SATB1 can either act as an activator or a repressor of transcription of multiple genes and mediate tissue-specific regulation [17]. In addition to the higher-order chromatin loop domain architecture, variety of histone

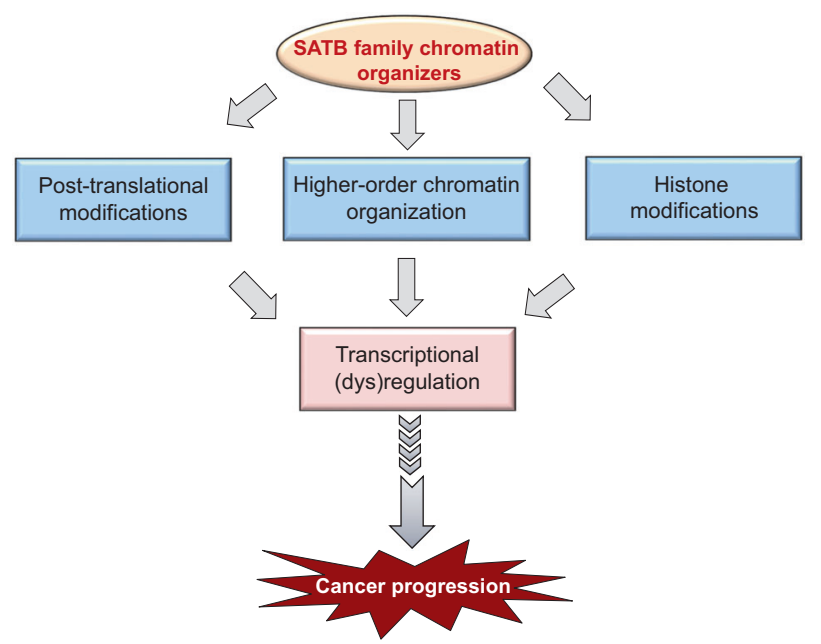

Fig. 1 Schematic representation of molecular mechanisms regulated by SATB family chromatin organizers leading to tumorigenesis and cancer progression. Tumor initiation is a multistep process triggered by series of changes in the genome. SATB family chromatin organizers modulate higher-order chromatin organization thereby reprogramming gene expression patterns leading to tumorigenesis and tumor progression. Along with regulation of higher-order chromatin organization, SATB proteins also mediate histone modifications which regulate gene expression leading to cancer progression. The accessibility of various transcription factors to chromatin is determined by posttranslational modifications of histones and thereby regulates gene expression. Post-translational modifications of SATB1 is known to regulate gene expression. SATB1 is known to be involved in inactivation of tumor suppressors and activation of oncogenes thereby leading to tumor progression. Thus, aberrant expression of SATB family chromatin organizers alters gene expression patterns and mediates cancer progression

modifications in chromatin also govern gene expression $[96,97]$. SATB1 regulates gene expression by mediating histone modifications as it recruits histone-modifying enzymes on promoters of oncogenes and also recruits HDAC1 on promoters of tumor suppressor genes [18, 87]. Further SATB proteins also act as a 'docking site' for various chromatin remodelers [28, 33] and its posttranslational modifications are important to regulate its functional role. Phosphorylation of SATB1 acts as a molecular switch regulating its transcriptional activity [33]. Although post-translational modifications of SATB2 have not been studied extensively so far, high extent of sequence homology and conservation of functional domains between SATB proteins indicate that SATB2 might exhibit similar functions. Together, these findings implicate SATB proteins as critical players in organizing nuclear structural framework required to establish the chromatin architecture to regulate global gene expression patterns. Further, their aberrant expression might lead to global transcriptional dysregulation leading to cancer progression (Fig. 1). 


\section{Dynamic expression patterns of SATB chromatin organizers governs stemness and differentiation}

SATB1 is a major regulator involved in differentiation by opening the chromatin structure around cell-type specific genes to enable transcription factors and chromatin remodeling proteins to bind. Role of SATB1 is well established in the differentiation of T-cell lineage; [38, 43] mouse embryonic stem cells [98] epidermal differentiation $[99,100]$, wherein the absence of SATB1 marks differentiated cellular state. SATB1 is a regulator of hematopoiesis [46, 101] and drives early erythroid differentiation [102-104]. In contrast, presence of SATB2 denotes differentiated state for osteoblasts [20, 105], cortical neuron [106] and skeletal development [20]. SATB proteins promote trophoblast stem cell (TS) renewal and inhibit differentiation by physically associating with a regulatory site of the TS cell stemassociated transcription factor, EOMES [107]. It has now been well appreciated that tumors contain a rare population of the stem-like cells defined by the property of self-renewal, multi-lineage differentiation, tumorinitiating capacity and are capable of recapitulating the heterogeneity of primary tumors [108, 109]. This rare sub-population of cells termed as cancer stem cells (CSCs) or tumor-initiating cells are responsible for the generation of tumor heterogeneity by deriving tumor cell hierarchy with CSCs at the apex followed by progenitors and differentiated cells. CSCs are involved in the generation of chemo- and radio-resistance culminating in disease relapse [110-112]. Recently, the role of SATB1 in the maintenance of breast cancer stem cells [113] was elucidated along with esophageal cancer [114]. SATB1 is shown to regulate CSCs through activation of Notch signaling and further mediates EMT through Snaill and Twist1 [113]. However, the understanding of regulatory mechanisms of CSCs and dissection of the relationship between CSCs and cancer metastasis requires further investigation.

SATB2 is proposed to serve as a diagnostic marker for CRC [115] and its expression was correlated with cancerassociated fibroblasts [116]. Role of SATB2 is speculated in the regulation of cancer stem cells in colorectal cancer [24], however, there is also a report stating SATB2 as a negative regulator of stemness in colorectal cancer [117] which might lead to its context-specific role. With the improved understanding of role SATB1 in metastasis and angiogenesis, elucidation of its role with respect to generation and maintenance of a stem or progenitor-like state is important since these are closely associated processes within a tumor.

\section{SATB chromatin organizers modulate hallmarks of cancer}

Aberrant expression of SATB1 and its association with an array of cancer types suggest its involvement in the modulation of higher-order chromatin organization leading to carcinogenesis. SATB1 mediated specific long-range chromosomal interactions between the mbr enhancer located within 3'-UTR of the BCL2 gene and the promoter regulate BCL2 expression during early apoptosis [118]. SATB1 is instrumental in regulating the dynamic equilibrium of apoptosis-controlling genes with antagonistic functions by modulating higher-order chromatin organization suggests that its aberrant expression might contribute to tumorigenesis by disrupting the co-regulated genes in apoptosis pathways [119]. Apart from disruption of apoptosis which is one of the hallmarks of cancer, SATB1 regulates estrogen signaling in breast cancer through miR-191 as the oncogenic player [120]. Knockdown of SATB1 is reported to inhibit angiogenesis, cell invasion, and metastasis in an array of cancer types thereby stating its role in governing hallmarks of cancer $[64,121]$. Underlying these hallmarks is genome instability, which generates the genetic diversity that expedites their acquisition, and inflammation. In this context, SATB1 expression is significantly associated with $\beta$-catenin overexpression and microsatellite stability [122]. Conceptual progress in the last decade has added two emerging hallmarks, namely reprogramming of energy metabolism and evading immune destruction to the previously established list [90]. In this context, SATB1 is speculated to be involved in the generation of hypoxia and metabolic stress in breast ductal carcinoma model [123], however, very little is known regarding the mechanistic details of the same.

\section{SATB chromatin organizers act as key regulators of EMT-MET switch and metastasis}

SATB1 overexpression is correlated with advanced stage, lymph node metastasis and distant metastasis in an array of cancer types including CRC [23], Prostate [124], esophageal squamous cell carcinoma [125], liver cancer [126], renal cell carcinoma [127], breast cancer [87], and pancreatic cancer [56]. In contrast, SATB2 acts as a negative regulator of Epithelial-Mesenchymal Transition (EMT) and metastasis in CRC $[69,128]$ and non-small-cell lung carcinoma (NSCLC) [25, 129]. Expression of SATB1 leads to upregulation of transcription factors associated with EMT such as Snail, Slug, Zeb1, and Zeb2 [130] and correspondingly downregulation of cell adhesion proteins such 

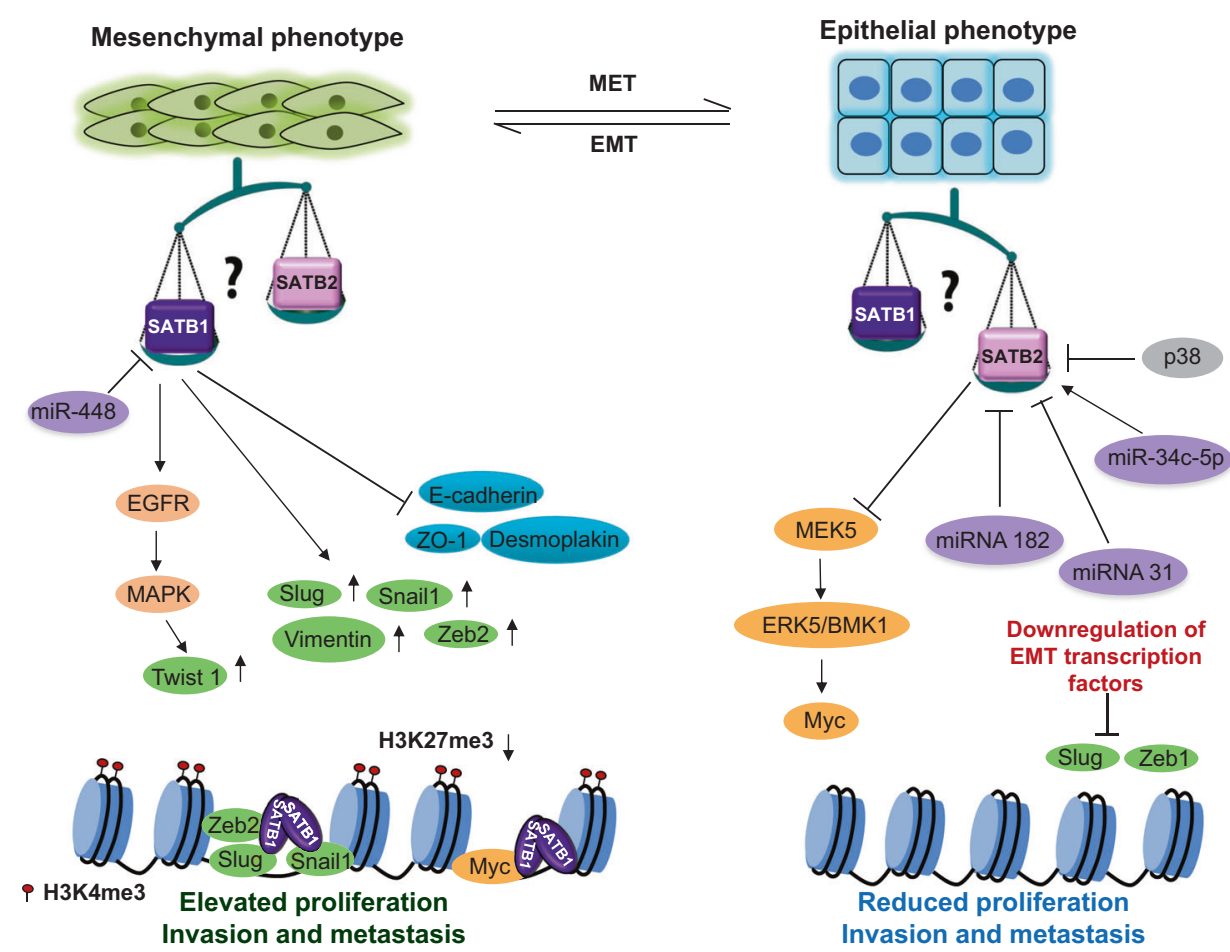

Fig. 2 Schematic representation of dynamic balance between expression patterns of SATB family chromatin organizers as regulators of EMT-MET cellular states during metastasis. Expression of SATB1 is positively correlated with upregulation of Epithelial-Mesenchymal Transition (EMT) associated transcription factors (Snail, Slug, Zeb1 and Zeb2) and negatively correlated with adhesion proteins (E cadherin, Desmoplakin, and ZO1) responsible for an epithelial phenotype (MET-mesenchymal-epithelial transition) of the cell. Higher expression of the respective SATB family member is schematically represented by the heavier pan of the balance. The microRNA miR448 negatively regulates SATB1 leading to EMT through upregulation

as E-cadherin, Desmoplakin, and ZO1 responsible for the epithelial phenotype of the cell [131]. SATB1 reprograms the expression of tumor growth and metastasis-associated genes to promote tumorigenesis and functionally overlaps with Wnt signaling critical for colorectal cancer tumorigenesis. An in-depth mechanistic investigation revealed that SATB1 shares a feedback regulatory network with TCF7L2/ $\beta$-catenin signaling and is required for Wnt signaling-dependent regulation of $\beta$-catenin [54]. miR-448 suppression leads to enhanced SATB1 expression which initiates amphiregulin-epidermal growth factor receptor signaling towards Twist1 expression through mitogenactivated protein kinase leading to EMT [132]. In case of SATB2, microRNAs miR-182 and miR-31 directly target the $3^{\prime}$ untranslated region ( $3^{\prime}$ UTR) of its mRNA and subsequently repress the expression of SATB2 at both mRNA and protein levels to promote cancer cell proliferation and metastasis $[133,134]$. Silencing of SATB2 mediated by methylated miR-34c-5p promoted the metastatic ability of CRC cells in vivo, enhancing the epithelial- of Twist1. In contrast, increased expression of SATB2 leads to downregulation of EMT transcription factors and promotes epithelial phenotype. SATB2 is regulated negatively by miRNA-31, miRNA182 and positively by miR-34c-5p, leading to downregulation of EMT related transcription factors. SATB1 promotes proliferation, invasion, and metastasis whereas SATB2 acts as a negative regulator of these processes. This suggests a state of dynamic balance between expression levels of SATB family chromatin organizers regulating cellular phenotypes involved in mediating EMT-MET during tumor invasion and metastasis

mesenchymal transition (EMT) [135]. Interestingly, inhibition of p38 upregulated SATB2 expression and reversed epithelial-mesenchymal transition in NSCLC cells [25]. SATB1 promoted c-Myc expression leading to enhanced cell invasion and metastatic abilities while SATB2 mediated downregulation of c-Myc via inactivation of ERK5, suggesting a dynamic balance between SATB chromatin organizers as a major factor for cell migration and metastasis [136]. Further, genome-wide analysis identified association of SATB1 target genes, revealed upregulation of a long non-coding RNA UCA1 along with increased H3K4 trimethylation (H3K4me3) and decreased $\mathrm{H} 3 \mathrm{~K} 27$ trimethylation (H3K27me3) levels suggesting activation of genes involved in metastasis [137] (Fig. 2).

EMT is a prerequisite for invasion and migration for cancer cells, however after migration of cancer cells to secondary metastatic site cancer cells undergo Mesenchymal-Epithelial Transition (MET) required for colonization [138, 139]. EMT and MET constitute dynamic interchangeable cellular states required for migration, 
invasion, and metastasis [140,141]. This suggests a state of dynamic balance between expression levels of SATB chromatin organizers regulating cellular phenotypes involved in mediating EMT-MET during tumor invasion and metastasis (Fig. 2). Multiple studies demonstrate that SATB1 is critical for enhanced cell survival, cell invasion and cell migration properties suggesting that it might prime tumor cells for metastasis. In contrast, SATB2 typically acts as a negative regulator for migration, invasion, and metastasis. However, reports stating the role of SATB2 in regulating EMT and metastasis have contested the above notion [24, 142]. Nevertheless, it would be more pertinent to understand the mechanistic regulation of both SATB chromatin organizers with respect to tumor metastasis and whether their expression levels act as a molecular switch governing EMT and MET during metastasis.

\section{Dynamic expression of SATB1 regulates tumor progression, immunity, and inflammation}

Role of SATB1 during T cell development is well established wherein it acts as a critical regulator in $\mathrm{CD} 4^{+} \mathrm{CD} 8^{+}$ thymocytes and during activation of $\mathrm{CD} 4^{+} \mathrm{T}$ cells $[33,36$, $37,143]$ and coordinates differentiation of specific $\mathrm{T}$ helper subtypes [38-40]. Strikingly, SATB1 is specifically downregulated in regulatory $\mathrm{T}$ cells $[36,43,44]$. SATB 1 is required for normal $\mathrm{T}$ cell development as well as by activated tumor recruited cytotoxic $\mathrm{T}$ lymphocyte (CTL) to elicit active immune response [144]. However, its elevated expression in tumor epithelial cells marks tumor aggressiveness [54, 87]. Increased SATB1 expression in intratumoral Tregs [145] and dendritic cells (DCs) [146] mediates tumor inflammation (Fig. 3).

A recent report implicated SATB1 as an important player to avoid $\mathrm{T}$ cell exhaustion phenotype and elicit anti-tumor immune response [41]. Transfer of tumor-primed SATB1deficient mixed population of $\mathrm{T}$ cells into the peritoneal cavity of mice bearing established orthotopic syngeneic ovarian tumors leads to accelerated tumor growth relative to the transfer of primed wild-type $T$ cells. It is believed that SATB1 regulates $T$ cells at multiple phases that would result in a "fixed" epigenetic landscape leading to an antitumor response [41]. Level of SATB1 is a critical mediator of the $\mathrm{T}$ cell exhaustion phenotype. Strikingly, a recent report indicated that PD1 signaling antagonizes CD28 costimulation, suggesting a feed-forward mechanism involving SATB1 whereby weak costimulation and/or signals from TGF- $\beta$ from the tumor microenvironment that leads to downregulation of SATB1. Reduction in SATB1 results in elevated PD1 levels, thereby suppressing costimulation, and further locking the $\mathrm{T}$ cells into an exhausted state [144]. This important finding bolsters the role of cell type-specific expression of SATB1 in tumor recruited CTLs which could be explored to induce an anti-tumor response. Amongst tumor recruited immune cells, FOXP $3^{+}$Tregs can markedly curtail host anti-tumor immune responses through inhibition of endogenous $\mathrm{T}$ cell response [147]. Intratumoral Tregs have a phenotype characterized by upregulated expression of FOXP3 mRNA and protein positively correlated with significantly increased expression of SATB1 as compared to normal Tregs where SATB1 is downregulated [44, 148, 149] (Fig. 3), suggesting SATB1 as an ideal target for antitumor Treg-based therapy [144].

Overexpression of the genome organizer SATB1 in tumor microenvironmental DCs drives genome-wide transcriptional program that globally transforms DCs. This leads to accelerated malignant tumor progression through an inflammatory axis that ablates anti-tumor immunity using the cytokine IL-6 and the immunosuppressive protein galectin-1 [145]. Galectin-1 secreted by inflammatory DCs inhibits $\mathrm{T}$ cell responses through multiple complementary mechanisms that affect DC immunocompetence [150]. Galectin- 1 causes apoptosis in Th1 and Th71 cells [151], renders effector T cells unresponsive by cross-linking GM1 ganglioside [152], and promotes the differentiation of tumor-associated Foxp3 + Treg cells [153]. Immunosuppressive DCs can also produce cytokines such as IL-10 or TGF- $\beta$ that directly inhibit the activity of anti-tumor T cells. Additionally, both IL-10 and TGF- $\beta$ promote the conversion of CD4 T cells into Treg cells, as well as the immunosuppressive activity of natural Tregs [154-156] (Fig. 3). Collectively, this suggests Dngr $1^{+}$DCs and galectin- 1 that is secreted by inflammatory DCs could serve as an ideal target for cancer therapy.

Elevated levels of SATB1 are known to be associated with tumorigenesis, tumor metastasis and progression. SATB1 collaborates with loss of p16 in cellular transformation through Rb-E2F pathway [157]. SATB1 is known to play an oncogenic role mediated through $\mathrm{FN} 1$ and PDGFRB [114]. SATB1 regulates molecular changes required for epithelial to mesenchymal transition, an important phenotypic change essential for metastasis. SATB1 regulates expression of epithelial to mesenchymal transition (EMT) associated transcription factors slug, snail and twist $[54,113,130]$. SATB1 is necessary and sufficient to regulate the expression of $\beta$-catenin, TCF family members and multiple downstream effectors and mediators for regulation of the Wnt signaling pathway. Mir et al. recently elucidated the mechanism of regulation of SATB1 though Wnt/B-catenin signaling [54]. They demonstrated that TCF7L2 binds to the Satb1 promoter and promotes H3K4 trimethylation, thereby directly regulates SATB1 expression. Hyperactivation of Wnt signaling induces occupancy of TCF7L2/ $\beta$-catenin complex on Satb1 promoter resulting 
in induction of SATB1 expression. Further, knockdown of TCF7L2 and $\beta$-catenin and their subsequent loss of occupancy on Satb1 promoter downregulated SATB1 as well as known downstream targets of Wnt signaling. Ectopic SATB1 expression in non-aggressive cells led to gene expression patterns consistent with aggressive-tumor phenotypes, acquiring metastatic activity in vivo. SATB1 delineates specific epigenetic modifications at target gene loci, directly upregulating metastasis-associated genes while downregulating tumor-suppressor genes [87]. Role of TGF $\beta$ in tumor cell migration and metastasis is well established and it is known to be secreted in the tumor microenvironment [158]. TGF $\beta$ secreted by tumor cells could downregulate SATB1 in CTLs leading to T cell exhaustion, transform SATB1 expressing immature DCs to inflammatory DCs which would inhibit tumor recruited CTLs and generate Tregs, thus, in turn, inhibiting CTLs. Therefore cell type-specific expression of SATB1 along with tumor microenvironment might act as primary determinants of tumor progression and tumor inflammation (Fig. 3). In vivo cell type-specific silencing of SATB1 specifically in tumor DCs and Tregs or neutralization of the immunosuppressive factors produced by SATB1 overexpressing DCs might emerge as promising immunotherapeutic alternatives in cancer therapy. Uncovering mechanisms to manipulate and increase SATB1 levels in CTLs might eventually enable new immunotherapies that would boost tumor immunity.

\section{SATB chromatin organizers as biomarkers for cancer prognosis}

To evaluate the association of SATB chromatin organizer expression within the tumor with the patient survival in an array of tumor types we used TCGA data [159]. Survival analysis was performed of TCGA dataset of patients from 14 cancer types in which gene expression obtained through RNA sequencing was correlated with patient survival data to evaluate the significance of the two members of the SATB family chromatin organizers towards cancer prognosis. Patients were sorted based on gene expression (read counts of RSEM RNAseqV2 normalized) from highest to least. Top $15-25 \%$ and bottom $15-25 \%$ patients based on SATB1 expression were characterized as SATB1 $1^{\text {hi }}$ and SATB $1^{\text {low }}$. Similarly, patients were sorted based on gene expression profiles as SATB2 ${ }^{\text {hi }}$ and SATB $2^{\text {low }}$. Statistical significance was calculated using log-rank $p$-value $\leq 0.05$ considered as significant. However, those cancer types with lower patient numbers were considered for survival analysis ( $p$-value $\leq 0.1)$ if they followed a survival trend since the increase in the number of patients would lead to the improved significance of the study. Survival analysis revealed that higher expression of both SATB1 and SATB2 was strongly correlated with poor patient survival for cervical squamous cell carcinoma, sarcoma, and stomach adenocarcinoma. Correlation of SATB1 is linked with aggressiveness in case of stomach adenocarcinoma and cervical squamous cell carcinoma, however, none of these studies had reported association of SATB2 [160, 161]. These findings are in agreement with earlier reports for sarcoma wherein expression of SATB1 and SATB2 was individually correlated to tumor aggressiveness in independent studies [162-164]. SATB1 expression correlated negatively with SATB2 which culminates in poor patient survival for colon adenocarcinoma, rectal adenocarcinoma, lung squamous cell carcinoma, uterine corpus endometrial carcinoma and liver hepatocellular carcinoma (Summarized in Table 1), which is well established in case of earlier two

Table 1 Correlation of expression of SATB family chromatin organizers with patient survival across cancer types

\begin{tabular}{|c|c|c|c|c|}
\hline Cancer subtypes & $\begin{array}{l}\text { Higher expression } \\
\text { of SATB1 and } \\
\text { SATB2 Poor } \\
\text { prognosis }\end{array}$ & $\begin{array}{l}\text { Higher expression } \\
\text { of SATB1 and } \\
\text { SATB2 Good } \\
\text { prognosis }\end{array}$ & $\begin{array}{l}\text { Higher expression of SATB1 } \\
\text { and lower expression of } \\
\text { SATB2 Poor prognosis }\end{array}$ & $\begin{array}{l}\text { Higher expression of SATB2 } \\
\text { and lower expression of } \\
\text { SATB1 Poor prognosis }\end{array}$ \\
\hline Urothelial bladder carcinoma & & & & $\checkmark$ \\
\hline Cervical squamous cell carcinoma & $\checkmark$ & & & \\
\hline Kidney renal clear cell carcinoma & & $\checkmark$ & & \\
\hline Acute meloid leukemia & & & & $\checkmark$ \\
\hline Low-grade glioma & & & & $\checkmark$ \\
\hline Liver hepatocellular carcinoma & & & $\checkmark$ & \\
\hline Lung squamous cell carcinoma & & & $\checkmark$ & \\
\hline Pancreatic adenocarcinoma & & & & $\checkmark$ \\
\hline Sarcoma & $\checkmark$ & & & \\
\hline Stomach adenocarcinoma & $\checkmark$ & & & \\
\hline Uterine corpus endometrial carcinoma & & & $\checkmark$ & \\
\hline $\mathrm{COAD}$ & & & $\sqrt{ }$ & \\
\hline READ & & & $\checkmark$ & \\
\hline Skin cutaneous melanoma & & & & $\checkmark$ \\
\hline
\end{tabular}




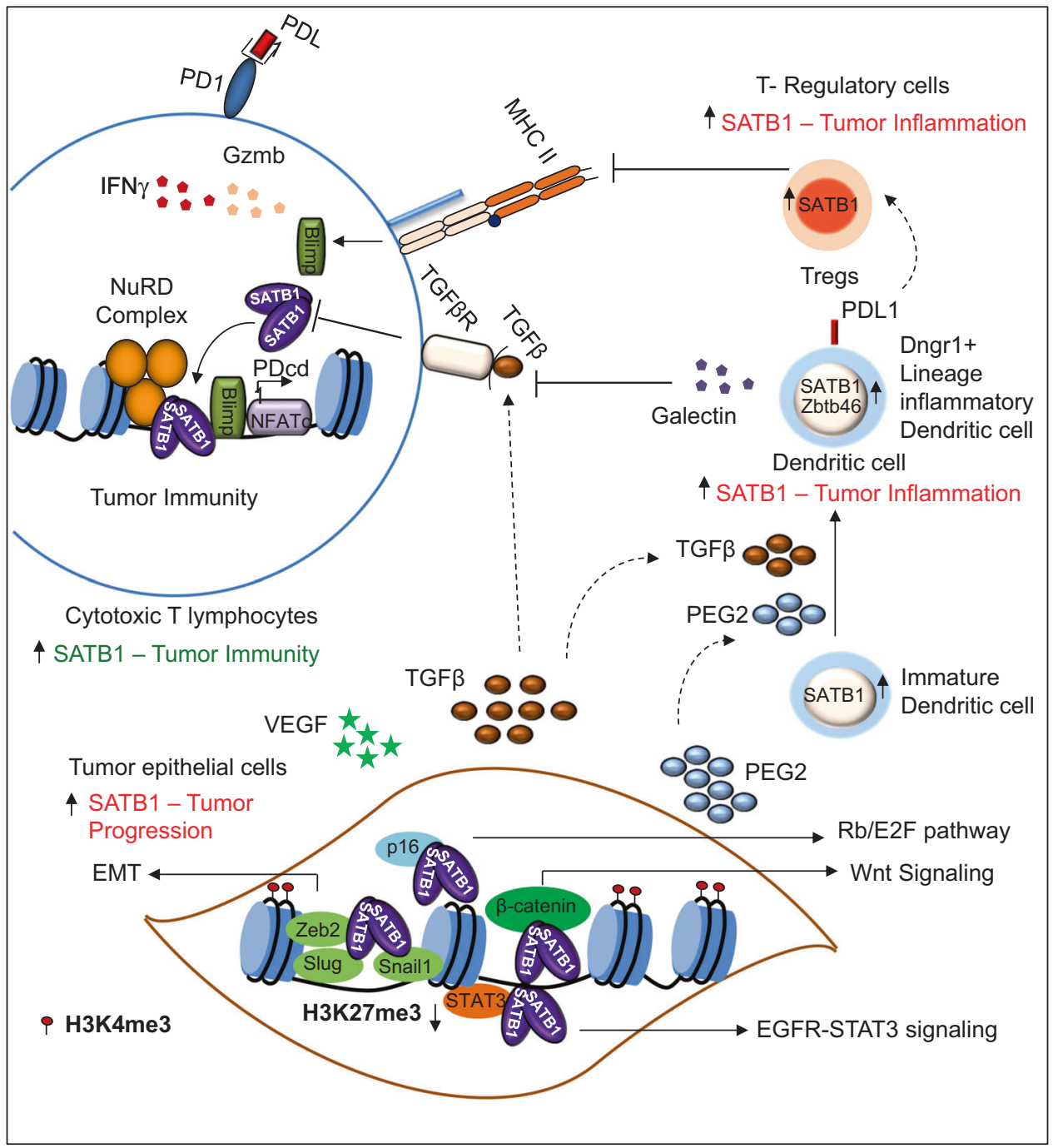

Fig. 3 Schematic representation of signaling pathways regulated by SATB1 in tumor epithelial cells, cytotoxic T lymphocytes (CTL), Dendritic cells (DC) and Tregs involved in tumor progression, tumor immunity, and inflammation respectively. Tumor microenvironment mediates cross-talk between the various cell types. TGF $\beta$ released in tumor niche downregulates SATB1 in CTLs due to which SATB1 is not available to interact with the NuRD complex required for transcription of $p d c d l$ gene, which ultimately leads to $\mathrm{T}$ cell exhaustion. This explains the requirement of SATB1 expression for active CTL response against the tumor antigen. TGF $\beta$ is also responsible for differentiation of SATB1 expressing immature DCs to Dnrg $1^{+}$lineage inflammatory DCs that secrete galectin which inhibits CTLs. These DCs also lead to the generation of Tregs. Intratumoral Tregs are marked by upregulation of SATB1 and are responsible for tumor inflammation. SATB1 regulates tumor progression in epithelial cells via $\mathrm{Wnt} / \beta$-catenin signaling and EGFR-STAT3 signaling. SATB1 mediates cellular transformation through the Rb-E2F pathway and promotes metastasis via the EMT associated transcription factors cancer types [19, 138], whereas the correlation with latter types is novel. Survival analysis revealed that in case of acute myeloid leukemia, low-grade glioma, urothelial bladder carcinoma and pancreatic adenocarcinoma higher expression of SATB2 and lower expression of SATB1 were determinant of poor patient survival (Fig. 4; Fig. 5). However, a recent study exhibited a lack of clarity for the correlation of expression of SATB 1 for urothelial bladder carcinoma [165]. Surprisingly, higher expression of both the SATB proteins conferred better patient survival for kidney renal clear cell carcinoma.
Our analysis is in agreement with the established fact of downregulation of both SATB chromatin organizers in kidney renal clear cell carcinoma $[125,166]$. Thus, the analysis presented here clearly indicates tissue-specific regulation of SATB chromatin organizers with respect to tumor aggressiveness (Fig. 4; Fig. 5). This comprehensive analysis across multiple tumor types strongly argues in favor of exploiting both members of the SATB family chromatin organizers to categorize cancer types, which can be effectively used to design molecularly targeted therapy. 


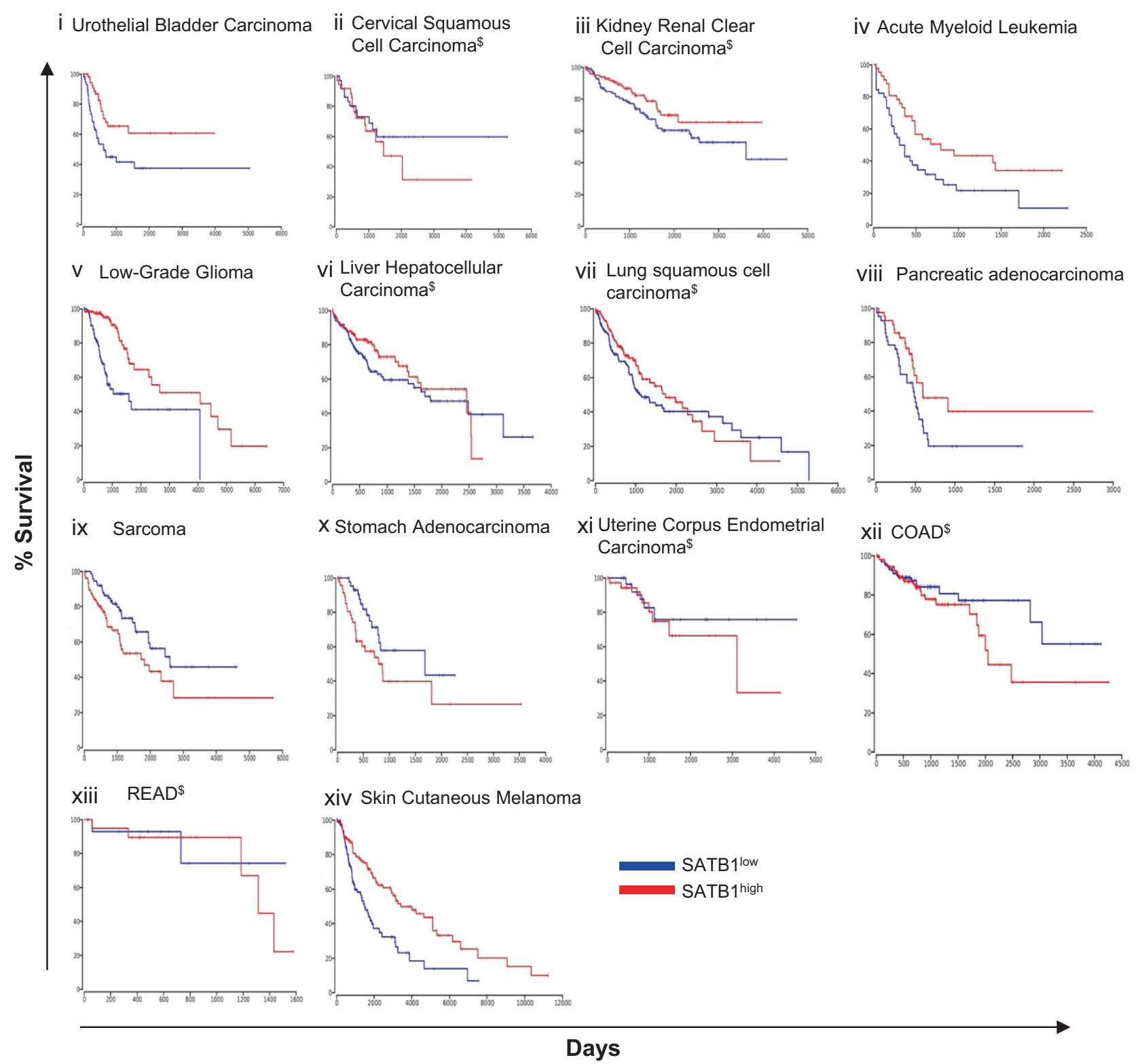

Fig. 4 Representative Kaplan Meier analysis plots for expression of SATB1 in various cancer types. TCGA gene expression data was downloaded for all available cancer types with patient clinical survival data (https://doi.org/10.7717/peerj-cs.67). Kaplan Meier survival analysis was performed with the correlation of expression of SATB1 with overall patient survival. The red line indicates higher expression of SATB1 whereas blue line indicates lower expression of SATB1. Data are plotted for Urothelial bladder carcinoma $(\mathrm{N}=60)$; cervical squamous cell carcinoma $(\mathrm{N}=39)$; kidney renal clear cell carcinoma $(\mathrm{N}=104)$; acute myeloid leukemia $(\mathrm{N}=45)$; low-grade glioma

\section{Future perspectives}

SATB chromatin organizers have been actively involved in tumor progression and metastasis in an array of malignancies. Expression of SATB1/2 is also linked to clinicopathological outcome, with dynamic and tissue-specific
$(\mathrm{N}=127)$; liver hepatocellular carcinoma $(\mathrm{N}=126)$; lung squamous cell carcinoma $(\mathrm{N}=136)$; pancreatic adenocarcinoma $(\mathrm{N}=43)$; sarcoma $(\mathrm{N}=77)$; stomach adenocarcinoma $(\mathrm{N}=49)$; uterine corpus endometrial carcinoma $(\mathrm{N}=37)$; colon adenocarcinoma $(\mathrm{N}=110)$; rectal adenocarcinoma $(\mathrm{N}=19)$; skin cutaneous melanoma $(\mathrm{N}=114)$ where $\mathrm{N}$ represents number of patients of respective cancer type based on SATB1 expression each for SATB $1^{\mathrm{hi}}$ and SATB $1^{\text {low }}$. Statistical significance was calculated using log-rank $p$-value $\leq 00.5 ; \$$ indicates dataset with lower patient numbers with $p$-value $\leq 0.1$

expression pattern and correlation with patient survival indicating it as an ideal marker for disease prognosis.

Notably, despite the growing literature on SATB1 in cancer, the relevance of post-translational modifications has been poorly studied. Akt phosphorylates SATB1 at serine 47 and protects SATB1 from apoptotic cleavage [167] and 


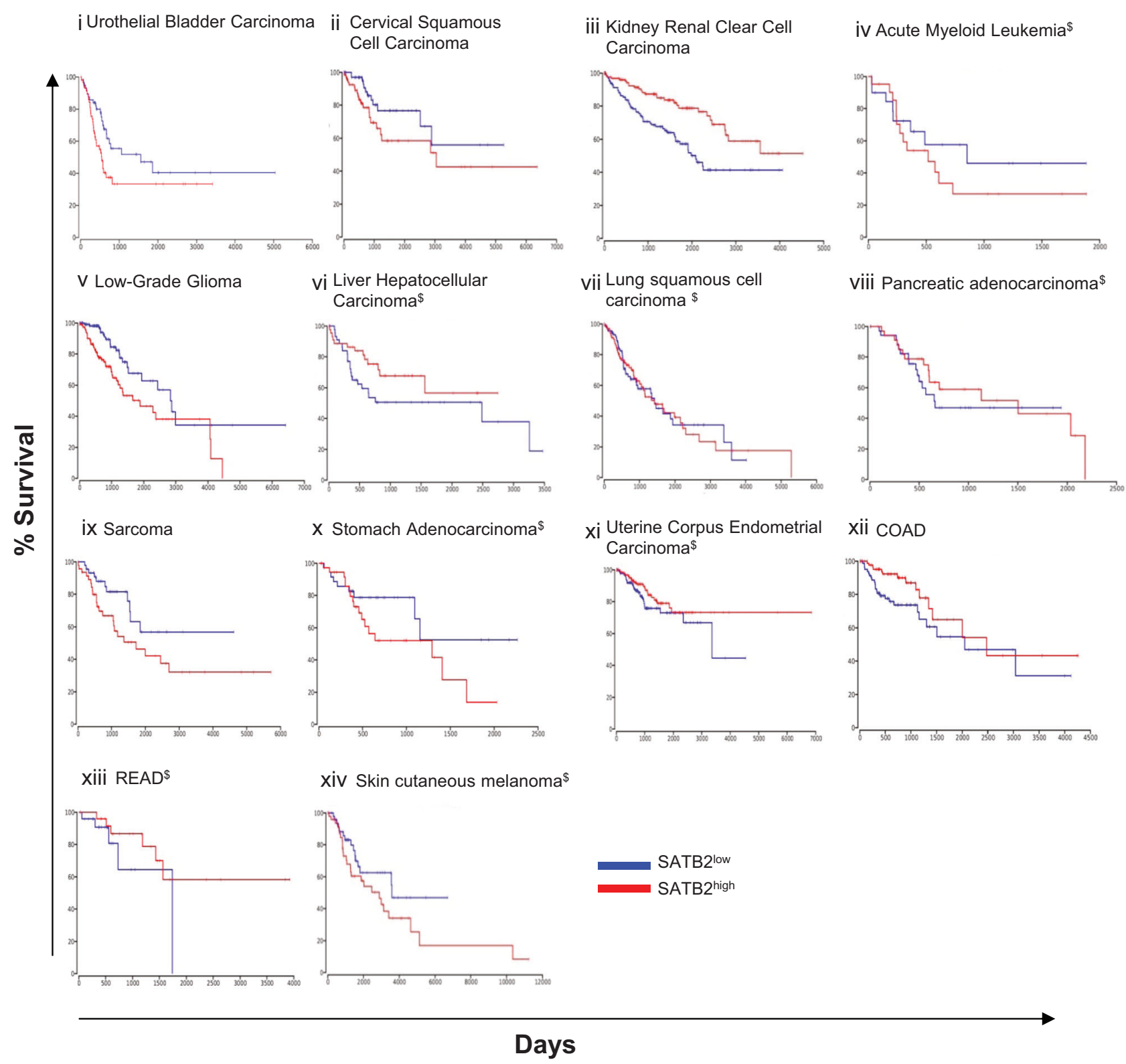

Fig. 5 Representative Kaplan Meier analysis plots for expression of SATB2 in cancer types. TCGA gene expression data was downloaded for all available cancer types with patient clinical survival data (https:// doi.org/10.7717/peerj-cs.67). Kaplan Meier survival analysis was performed with the correlation of expression of SATB2 with overall patient survival. The red line indicates higher expression of SATB2 whereas blue line indicates lower expression of SATB2. Data are plotted for Urothelial Bladder Carcinoma $(\mathrm{N}=60)$; Cervical Squamous Cell Carcinoma $(\mathrm{N}=71)$; Kidney Renal Clear Cell Carcinoma $(\mathrm{N}=130)$; Acute Myeloid Leukemia $(\mathrm{N}=21)$; Low-Grade Glioma

$(\mathrm{N}=127)$; Liver Hepatocellular Carcinoma $(\mathrm{N}=46)$; Lung squamous cell carcinoma $(\mathrm{N}=97)$; Pancreatic Adenocarcinoma $(\mathrm{N}=35)$; Sarcoma $(\mathrm{N}=46)$; Stomach Adenocarcinoma $(\mathrm{N}=37)$; Uterine Corpus Endometrial Carcinoma $(\mathrm{N}=135)$; Colon Adenocarcinoma $(\mathrm{N}=88)$; Rectal Adenocarcinoma $(\mathrm{N}=25)$; skin cutaneous melanoma $(\mathrm{N}=50)$, where $\mathrm{N}$ represents number of patients of respective cancer type based on SATB2 expression each for SATB2 $2^{\text {hi }}$ and SATB2 $2^{\text {low }}$. Statistical significance was calculated using log-rank $p$-value $\leq 00.5 ; \$$ indicates dataset with lower patient numbers with $p$-value $\leq 0.1$

levels of phosphorylated SATB1 correlate with glioma prognosis [58]. The promyelocytic leukemia oncoprotein physically and functionally interacts with SATB1 to organize the major histocompatibility complex class I locus into distinct higher-order chromatin-loop structures [32].
Phosphorylation status of SATB1 at serine 185 governs its mutually exclusive association with HDAC1 and PCAF; whereas acetylation at lysine 136 impairs the DNA-binding activity of SATB1 [33]. Further, phosphorylationdependent interaction of SATB1 and PIAS1 directs 
SUMO-regulated caspase cleavage of SATB1 [168, 169]. Recently the role of sumoylation-deficient SATB1 has been implicated in cellular migration [170]. SUMO modification of SATB2 is known to modulate immunoglobulin mu gene expression [27]. However, its implications with respect to cancer are not studied so far. Therefore it is important to understand post-translational modifications such as phosphorylation, acetylation, and SUMOylation associated with SATB chromatin organizers that may contribute to reprogramming of gene expression patterns during tumor metastasis.

SATB1 is an attractive therapeutic target for cancer therapy and although a couple of drugs have been explored to exhibit anticancer activity via downregulation of SATB1, the underlying molecular mechanisms are still unclear. Baicalein has been shown to suppress SATB1 protein expression in a time- and dose-dependent manner, exerting anti-proliferative and anti-migratory effects [171]. At the molecular level, a decrease in EMT and cell cycle molecules has been found [172]. Likewise, hydrophobic statins such as simvastatin and fluvastatin have been shown to downregulate SATB1 possibly acting at the posttranslational level [173]. Proteomic approaches should be employed to understand the repertoire of proteins interacting with SATB chromatin organizers. The interaction interface could be used for the development of small molecular weight inhibitors enabling targeted therapy.

Recently the role of SATB1 in hematopoiesis has been characterized. SATB1 regulates maintenance of hematopoietic stem cell (HSC) multipotency and leads to the generation of HSC heterogeneity [174]. More specifically, SATB1 is known to promote lymphoid differentiation from the hematopoietic stem-progenitor cell [103]. SATB1 conditional knockout mice in which $S A T B 1$ gene is specifically deleted from hematopoietic cells, develop Sjögren's Syndrome suggesting the role of SATB1 dysregulation in HSCs driving diseased state [175]. Malignant cancer stage is characterized by altered hematopoietic differentiation resulting in an increase in myeloid output. Altered myelopoiesis along with SATB1 overexpression converge to transform DCs from an immunostimulatory to an immunosuppressive, tumor-promoting cell type [176].

Immunotherapy is recently much-appreciated treatment strategy in cancer therapy due to its least toxic nature. In this context, SATB1-derived epitope has been implicated as the immune target for cancer vaccine development [177]. In contrast, SATB1 overexpression has also been shown to act as a tumor promoter in cancer-associated dendritic cells [146]. By promoting the differentiation of dendritic cells, including inflammatory DCs infiltrating tumors, SATB1 has been shown in ovarian carcinoma to result in an immunosuppressive phenotype. Consequently, in vivo silencing of
SATB1 in tumor-associated DCs was found to boost protective immunity. SATB1 regulates tumor progression by its downregulation in tumor recruited CTLs, and upregulation in tumor epithelial cells and tumor recruited Tregs. Thus SATB1 regulation is cell type-specific leading to aggressive phenotype and metastasis.

The availability of adequate tools for quantification and analysis, appropriate tumor models, novel therapeutic drugs that mediate tissue-specific knockdown of SATB family chromatin organizers will not only establish its utility as a prognostic marker, but also elucidate their possible use as a therapeutic target.

Acknowledgements Work was supported by intramural funding from IISER Pune to SG. RN is supported by a postdoctoral fellowship from the Department of Biotechnology, Government of India, and the national postdoctoral fellowship of the Department of Science and Technology, Science and Engineering Research Board, Government of India. Authors wish to thank Drs. Prachi Patil for discussion and Chandan Kumar Sinha for insightful comments on the manuscript.

Author contributions RN and SG conceived the ideas, analyzed the data and wrote the manuscript.

\section{Compliance with ethical standards}

Conflict of interest The authors declare that they have no conflict of interest.

\section{References}

1. Fry CJ, Peterson CL. Chromatin remodeling enzymes: who's on first? Curr Biol. 2001;11:R185-R197.

2. Zhang Y, Reinberg D. Transcription regulation by histone methylation: interplay between different covalent modifications of the core histone tails. Genes Dev. 2001;15:2343-60.

3. Freiman RN, Tjian R. Regulating the regulators: lysine modifications make their mark. Cell. 2003;112:11-17.

4. Lai AY, Wade PA. Cancer biology and NuRD: a multifaceted chromatin remodelling complex. Nat Rev Cancer. 2011;11:58896.

5. Schubeler D, Francastel C, Cimbora DM, Reik A, Martin DI, Groudine M. Nuclear localization and histone acetylation: a pathway for chromatin opening and transcriptional activation of the human beta-globin locus. Genes Dev. 2000;14:940-50.

6. Spector DL. The dynamics of chromosome organization and gene regulation. Annu Rev Biochem. 2003;72:573-608.

7. Brown KE. Chromatin folding and gene expression: new tools to reveal the spatial organization of genes. Chromosome Res. 2003;11:423-33.

8. De Laat W, Grosveld F. Spatial organization of gene expression: the active chromatin hub. Chromosome Res. 2003;11:447-59.

9. Recillas-Targa F, Razin SV. Chromatin domains and regulation of gene expression: familiar and enigmatic clusters of chicken globin genes. Crit Rev Eukaryot Gene Expr. 2001;11:227-42.

10. Margueron R, Trojer P, Reinberg D. The key to development: interpreting the histone code? Curr Opin Genet Dev. 2005;15:163-76. 
11. Millard CJ, Fairall L, Schwabe JW. Towards an understanding of the structure and function of MTA1. Cancer Metastas Rev. 2014;33:857-67.

12. Kolla V, Naraparaju K, Zhuang T, Higashi M, Kolla S, Blobel GA, et al. The tumour suppressor CHD5 forms a NuRD-type chromatin remodelling complex. Biochem J. 2015;468:345-52.

13. Clapier CR, Iwasa J, Cairns BR, Peterson CL. Mechanisms of action and regulation of ATP-dependent chromatin-remodelling complexes. Nat Rev Mol Cell Biol. 2017;18:407-22.

14. Watanabe R, Kanno SI, Mohammadi Roushandeh A, Ui A, Yasui A. Nucleosome remodelling, DNA repair and transcriptional regulation build negative feedback loops in cancer and cellular ageing. Philos Trans R Soc Lond B Biol Sci. 2017;372:1731

15. Galande S, Purbey PK, Notani D, Kumar PP. The third dimension of gene regulation: organization of dynamic chromatin loopscape by SATB1. Curr Opin Genet Dev. 2007;17:408-14.

16. Krangel MS. T cell development: better living through chromatin. Nat Immunol. 2007;8:687-94.

17. Mir R, Pradhan SJ, Galande S. Chromatin organizer SATB1 as a novel molecular target for cancer therapy. Curr Drug Targets. 2012;13:1603-15.

18. Kohwi-Shigematsu T, Kohwi Y, Takahashi K, Richards HW, Ayers SD, Han HJ, et al. SATB1-mediated functional packaging of chromatin into loops. Methods. 2012;58:243-54.

19. Brocato J, Costa M. SATB1 and 2 in colorectal cancer. Carcinogenesis. 2015;36:186-91.

20. Dobreva G, Chahrour M, Dautzenberg M, Chirivella L, Kanzler B, Fariñas I, et al. SATB2 is a multifunctional determinant of craniofacial patterning and osteoblast differentiation. Cell. 2006;125:971-86.

21. Britanova O, Akopov S, Lukyanov S, Gruss P, Tarabykin V. Novel transcription factor Satb2 interacts with matrix attachment region DNA elements in a tissue-specific manner and demonstrates cell-type-dependent expression in the developing mouse CNS. Eur J Neurosci. 2005;21:658-68.

22. Ding M, Pan J, Guo Z, Liu Q, Yang C, Mao L. SATB1 is a Novel Molecular Target for Cancer Therapy. Cancer Invest. 2018;36:28-36.

23. Zhang S, Tong YX, Xu XS, Lin H, Chao TF. Prognostic significance of SATB1 in gastrointestinal cancer: a meta-analysis and literature review. Oncotarget. 2017;8:48410-23.

24. Yu W, Ma Y, Shankar S, Srivastava RK. SATB2/ $\beta$-catenin/TCFLEF pathway induces cellular transformation by generating cancer stem cells in colorectal cancer. Sci Rep. 2017;7:10939.

25. Kucuksayan H, Akca $\mathrm{H}$. The crosstalk between p38 and Akt signaling pathways orchestrates EMT by regulating SATB2 expression in NSCLC cells. Tumour Biol. 2017;39:1010428317706212.

26. Bian T, Zhao J, Feng J, Zhang Q, Qian L, Liu J, et al. Combination of cadherin-17 and SATB homeobox 2 serves as potential optimal makers for the differential diagnosis of pulmonary enteric adenocarcinoma and metastatic colorectal adenocarcinoma. Oncotarget. 2017;8:63442-52.

27. Dobreva G, Dambacher J, Grosschedl R. SUMO modification of a novel MAR-binding protein, SATB2, modulates immunoglobulin mu gene expression. Genes Dev. 2003;17:3048-61.

28. Yasui D, Miyano M, Cai S, Varga-Weisz P, Kohwi-Shigematsu T. SATB1 targets chromatin remodelling to regulate genes over long distances. Nature. 2002;419:641-5.

29. Cai S, Han HJ, Kohwi-Shigematsu T. Tissue-specific nuclear architecture and gene expression regulated by SATB1. Nat Genet. 2003;34:42-51.

30. Scheuermann RH, Garrard WT. MARs of antigen receptor and co-receptor genes. Crit Rev Eukaryot Gene Expr. 1999;9:295310 .
31. Cai S, Lee CC, Kohwi-Shigematsu T. SATB1 packages densely looped, transcriptionally active chromatin for coordinated expression of cytokine genes. Nat Genet. 2006;38:1278-88.

32. Kumar PP, Bischof O, Purbey PK, Notani D, Urlaub H, Dejean A, et al. Functional interaction between PML and SATB1 regulates chromatin-loop architecture and transcription of the MHC class I locus. Nat Cell Biol. 2007;9:45-56.

33. Kumar P, Purbey PK, Sinha CK, Notani D, Limaye A, Jayani RS, et al. Phosphorylation of SATB1, a global gene regulator, acts as a molecular switch regulating its transcriptional activity in vivo. Mol Cell. 2006;22:231-43.

34. FitzPatrick DR, Carr IM, McLaren L, Leek JP, Wightman P, Williamson K, et al. Identification of SATB2 as the cleft palate gene on 2q32-q33. Hum Mol Genet. 2003;12:2491-501.

35. Agrelo R, Souabni A, Novatchkova M, Haslinger C, Leeb M, Komnenovic V, et al. SATB1 defines the developmental context for gene silencing by Xist in lymphoma and embryonic cells. Dev Cell. 2009;16:507-16.

36. Gottimukkala KP, Jangid R, Patta I, Sultana DA, Sharma A, Misra-Sen J, et al. Regulation of SATB1 during thymocyte development by TCR signaling. Mol Immunol. 2016;77:34-43.

37. Hao B, Naik AK, Watanabe A, Tanaka H, Chen L, Richards HW, et al. An anti-silencer- and SATB1-dependent chromatin hub regulates Rag1 and Rag2 gene expression during thymocyte development. J Exp Med. 2015;212:809-24.

38. Notani D, Gottimukkala KP, Jayani RS, Limaye AS, Damle MV, Mehta S, et al. Global regulator SATB1 recruits beta-catenin and regulates $\mathrm{T}(\mathrm{H}) 2$ differentiation in Wnt-dependent manner. PLoS Biol. 2010;8:e1000296.

39. Ahlfors H, Limaye A, Elo LL, Tuomela S, Burute M, Gottimukkala KV, et al. SATB1 dictates expression of multiple genes including IL-5 involved in human T helper cell differentiation. Blood. 2010;116:1443-53.

40. Hwang SS, SW Jang, Lee GR. RHS6-mediated chromosomal looping and nuclear substructure binding is required for Th2 cytokine gene expression. Biochim Biophys Acta. 2017;1860:383-91.

41. Stephen TL, Payne KK, Chaurio RA, Allegrezza MJ, Zhu H, Perez-Sanz J, et al. SATB1 expression governs epigenetic repression of $\mathrm{PD}-1$ in tumor-reactive $\mathrm{T}$ cells. Immunity. 2017;46:51-64.

42. Kondo M, Tanaka Y, Kuwabara T, Naito T, Kohwi-Shigematsu T, Watanabe A. SATB1 plays a critical role in establishment of immune tolerance. J Immunol. 2016;196:563-72.

43. Kitagawa Y, Ohkura N, Kidani Y, Vandenbon A, Hirota K, Kawakami R, et al. Guidance of regulatory $\mathrm{T}$ cell development by Satb1-dependent super-enhancer establishment. Nat Immunol. 2017;18:173-83.

44. Beyer M, Thabet Y, Müller RU, Sadlon T, Classen S, Lahl K, et al. Repression of the genome organizer SATB1 in regulatory $\mathrm{T}$ cells is required for suppressive function and inhibition of effector differentiation. Nat Immunol. 2011;12:898-907.

45. Kurkewich JL, Hansen J, Klopfenstein N, Zhang H, Wood C, Boucher A, et al. The miR-23a 27a 24-2 microRNA cluster buffers transcription and signaling pathways during hematopoiesis. PLoS Genet. 2017;13:e1006887.

46. Satoh Y, Yokota T, Sudo T, Kondo M, Lai A, Kincade PW, et al. The Satb1 protein directs hematopoietic stem cell differentiation toward lymphoid lineages. Immunity. 2013;38:1105-15.

47. Peng YR, Tran NM, Krishnaswamy A, Kostadinov D, Martersteck EM, Sanes JR. Satb1 regulates contactin 5 to pattern dendrites of a mammalian retinal ganglion cell. Neuron. 2017;95:869-83.

48. Wang F, Tidei JJ, Polich ED, Gao Y, Zhao H, Perrone-Bizzozero NI, et al. Positive feedback between RNA-binding protein $\mathrm{HuD}$ 
and transcription factor SATB1 promotes neurogenesis. Proc Natl Acad Sci USA. 2015;112:E4995-5004.

49. Balamotis MA, Tamberg N, Woo YJ, Li J, Davy B, KohwiShigematsu T, et al. Satb1 ablation alters temporal expression of immediate early genes and reduces dendritic spine density during postnatal brain development. Mol Cell Biol. 2012;32:333-47.

50. Zhou LQ, Wu J, Wang WT, Yu W, Zhao GN, Zhang P, et al. The AT-rich DNA-binding protein SATB2 promotes expression and physical association of human $(\mathrm{G}) \gamma$ - and $(\mathrm{A}) \gamma$-globin genes. J Biol Chem. 2012;287:30641-52.

51. Britanova O, Depew MJ, Schwark M, Thomas BL, Miletich I, Sharpe P, et al. Satb2 haploinsufficiency phenocopies 2q32-q33 deletions, whereas loss suggests a fundamental role in the coordination of jaw development. Am J Hum Genet. 2006;79:668-78.

52. Britanova O, de Juan Romero C, Cheung A, Kwan KY, Schwark M, Gyorgy A, et al. Satb2 is a postmitotic determinant for upperlayer neuron specification in the neocortex. Neuron. 2008;57:378-92.

53. Alcamo EA, Chirivella L, Dautzenberg M, Dobreva G, Fariñas I, Grosschedl R, et al. Satb2 regulates callosal projection neuron identity in the developing cerebral cortex. Neuron. 2008;57:36477.

54. Mir R, Pradhan SJ, Patil P, Mulherkar R, Galande S. Wnt//catenin signaling regulated SATB1 promotes colorectal cancer tumorigenesis and progression. Oncogene. 2016;35:1679-91.

55. Zheng J. Is SATB1 a master regulator in breast cancer growth and metastasis? Women's Health. 2008;4:329-32.

56. Elebro J, Heby M, Gaber A, Nodin B, Jonsson L, Fristedt R, et al. Prognostic and treatment predictive significance of SATB1 and SATB2 expression in pancreatic and periampullary adenocarcinoma. J Transl Med. 2014;12:289.

57. Deng YF, Zhou DN, Pan ZY, Yin P, et al. Aberrant SATB1 expression is associated with Epstein-Barr virus infection, metastasis and survival in human nasopharyngeal cells and endemic nasopharyngeal carcinoma. Int $\mathrm{J}$ Clin Exp Pathol. 2014;7:2454-61.

58. Han B, Luan L, Xu Z, Wu B. Expression and biological roles of SATB1 in human bladder cancer. Tumour Biol. 2013;34:29439.

59. Mao L, Yang C, Wang J, Li W, Wen R, Chen J, et al. SATB1 is overexpressed in metastatic prostate cancer and promotes prostate cancer cell growth and invasion. J Transl Med. 2013;11:111.

60. Wang Q, Yang CS, Ma ZX, Chen JC, Zheng JN, Sun XQ, et al. Inhibition of prostate cancer DU145 cell growth with small interfering RNA targeting the SATB1 gene. Exp Ther Med. 2018;15:3028-33.

61. Selinger CI, Cooper WA, Al-Sohaily S, Mladenova DN, Pangon $\mathrm{L}$, Kennedy CW, et al. Loss of special AT-rich binding protein 1 expression is a marker of poor survival in lung cancer. $\mathrm{J}$ Thorac Oncol. 2011;6:1179-89.

62. Xiang J, Zhou L, Li S, Xi X, Zhang J, Wang Y, et al. AT-rich sequence binding protein 1 : contribution to tumor progression and metastasis of human ovarian carcinoma. Oncol Lett. 2012;3:865-70.

63. Tu W, Luo M, Wang Z, Yan W, Xia Y, Deng H, et al. Upregulation of SATB1 promotes tumor growth and metastasis in liver cancer. Liver Int. 2012;32:1064-78.

64. Chu SH, Ma YB, Feng DF, Zhang H, Zhu ZA, Li ZQ, et al. Upregulation of SATB1 is associated with the development and progression of glioma. J Transl Med. 2012;10:149.

65. Fredholm S, Willerslev-Olsen A, Met Ö, Kubat L, Gluud M, Mathiasen SL et al. Special AT-rich-binding1 protein (SATB1) in malignant T cells. J Invest Dermatol. 2018. https://doi.org/10. 1016/j.jid.2018.03.1526.
66. Sun J, Yi S, Qiu L, Fu W, Wang A, Liu F, et al. SATB1 defines a subtype of cutaneous CD30 + lymphoproliferative disorders associated with a T-helper 17 cytokine profile. J Invest Dermatol. 2018. https://doi.org/10.1016/j.jid.2018.02.028.

67. Feng Y, Wang X, Wang Q. Expression of SATB1 and E-cad in tissues of patients with endometrial carcinoma and the relationship with clinicopathological features. Exp Ther Med. 2018;15:4339-43.

68. Cheng C, Wan F, Liu L, Zeng F, Xing S, Wu X, et al. Overexpression of SATB1 is associated with biologic behavior in human renal cell carcinoma. PLOS ONE. 2014;9:e97406.

69. Iorns E, Hnatyszyn HJ, Seo P, Clarke J, Ward T, Lippman M. The role of SATB1 in breast cancer pathogenesis. J Natl Cancer Inst. 2010;102:1284-96.

70. Hanker LC, Karn T, Mavrova-Risteska L, Ruckhaberle E, Gaetje $\mathrm{R}$, Holtrich U, et al. SATB1 gene expression and breast cancer prognosis. Breast. 2011;20:309-13.

71. Al-Sohaily S, Henderson C, Selinger C, Pangon L, Segelov E, Kohonen-Corish MRJ, et al. Loss of special AT-rich sequencebinding protein 1 (SATB1) predicts poor survival in patients with colorectal cancer. Histopathology. 2014;65:155-63.

72. Wang S, Wan F, Liu L, Zeng F, Xing S, Wu X, et al. Downregulated expression of SATB2 is associated with metastasis and poor prognosis in colorectal cancer. J Pathol. 2009;219:114-22.

73. Liu TR, Xu LH, Yang AK, Zhong Q, Song M, Li MZ, et al. Decreased expression of SATB2: a novel independent prognostic marker of worse outcome in laryngeal carcinoma patients. PLoS ONE. 2012;7:e40704.

74. Seong BK, Lau J, Adderley T, Kee L, Chaukos D, Pienkowska $M$, et al. SATB2 enhances migration and invasion in osteosarcoma by regulating genes involved in cytoskeletal organization. Oncogene. 2015;34:3582-92.

75. de Belle I, Cai S, Kohwi-Shigematsu T. The genomic sequences bound to special AT-rich sequence-binding protein 1 (SATB1) in vivo in Jurkat $\mathrm{T}$ cells are tightly associated with the nuclear matrix at the bases of the chromatin loops. J Cell Biol. 1998;141:335-48.

76. Kohwi-Shigematsu T, Poterlowicz K, Ordinario E, Han HJ, Botchkarev VA, Kohwi Y. Genome organizing function of SATB1 in tumor progression. Semin Cancer Biol. 2013;23:7279.

77. Cremer T, Cremer C. Chromosome territories, nuclear architecture and gene regulation in mammalian cells. Nat Rev Genet. 2001;2:292-301.

78. Cremer T, Cremer M, Dietzel S, Muller S, Solovei I, Fakan S. Chromosome territories-a functional nuclear landscape. Curr Opin Cell Biol. 2006;18:307-16.

79. Gibcus JH, Samejima K, Goloborodko A, Samejima I, Naumova $\mathrm{N}$, Nuebler J, et al. A pathway for mitotic chromosome formation. Science. 2018;359:eaao6135.

80. Shilatifard A. Chromatin modifications by methylation and ubiquitination: implications in the regulation of gene expression. Annu Rev Biochem. 2006;75:243-69.

81. Groth A, Rocha W, Verreault A, Almouzni G. Chromatin challenges during DNA replication and repair. Cell. 2007;128:72133.

82. Kouzarides T. Chromatin modifications and their function. Cell. 2007;128:693-705.

83. Meaburn KJ, Misteli T. Locus-specific and activity-independent gene repositioning during early tumorigenesis. J Cell Biol. 2008;180:39-50.

84. Misteli T. Beyond the sequence: cellular organization of genome function. Cell. 2007;128:787-800.

85. Göndör A. Dynamic chromatin loops bridge health and disease in the nuclear landscape. Semin Cancer Biol. 2013;23:90-8. 
86. Borghesi L. Hematopoiesis in steady-state versus stress: selfrenewal, lineage fate choice, and the conversion of danger signals into cytokine signals in hematopoietic stem cells. J Immunol. 2014;193:2053-8.

87. Han HJ, Russo J, Kohwi Y, Kohwi-Shigematsu T. SATB1 reprogrammes gene expression to promote breast tumour growth and metastasis. Nature. 2008;452:187-93.

88. Shannon MF. A nuclear address with influence. Nat Genet. 2003;34:4-6.

89. Reisman D, Glaros S, Thompson EA. The SWI/SNF complex and cancer. Oncogene. 2009;28:1653-68.

90. Helming KC, Wang X, Roberts CWM. Vulnerabilities of mutant SWI/SNF complexes in cancer. Cancer Cell. 2014;26:309-17.

91. Chai J, Charboneau AL, Betz BL, Weissman BE. Loss of the hSNF5 gene concomitantly inactivates p21CIP/WAF1 and p16INK4a activity associated with replicative senescence in A204 rhabdoid tumor cells. Cancer Res. 2005;65:10192-8.

92. Arnaud O, Le Loarer F, Tirode F. BAFfling pathologies: alterations of BAF complexes in cancer. Cancer Lett. 2018;419:266-79.

93. Chatterjee A, Rodger EJ, Eccles MR. Epigenetic drivers of tumourigenesis and cancer metastasis. Semin Cancer Biol. 2017. https://doi.org/10.1016/j.semcancer.2017.08.004.

94. Deng B, Melnik S, Cook PR. Transcription factories, chromatin loops, and the dysregulation of gene expression in malignancy. Semin Cancer Biol. 2013;23:65-71.

95. Mansouri L, Wierzbinska JA, Plass C, Rosenquist R. Epigenetic deregulation in chronic lymphocytic leukemia: Clinical and biological impact. Semin Cancer Biol. 2018. https://doi.org/10. 1016/j.semcancer.2018.02.001.

96. Strahl BD, Allis CD. The language of covalent histone modifications. Nature. 2000;403:41-5

97. Allis CD, Berger SL, Cote J, Dent S, Jenuwien T, Kouzarides T, et al. New nomenclature for chromatin-modifying enzymes. Cell. 2007;131:633-6.

98. Savarese F, Dávila A, Nechanitzky R, De La Rosa-Velazquez I, Pereira CF, Engelke R, et al. Satb1 and Satb2 regulate embryonic stem cell differentiation and Nanog expression. Genes Dev. 2009;23:2625-38.

99. Mardaryev AN, Gdula MR, Yarker JL, Emelianov VU, Poterlowicz K, Sharov AA, et al. p63 and Brg1 control developmentally regulated higher-order chromatin remodelling at the epidermal differentiation complex locus in epidermal progenitor cells. Development. 2014;141:101-11.

100. Fessing MY, Mardaryev AN, Gdula MR, Sharov AA, Sharova TY, Rapisarda V, et al. p63 regulates Satb1 to control tissuespecific chromatin remodeling during development of the epidermis. J Cell Biol. 2011;194:825-39.

101. Will B, Vogler TO, Bartholdy B, Garrett-Bakelman F, Mayer J, Barreyro L, et al. Satb1 regulates the self-renewal of hematopoietic stem cells by promoting quiescence and repressing differentiation commitment. Nat Immunol. 2013;14:437-45.

102. Wen J, Huang S, Rogers H, Dickinson LA, Kohwi-Shigematsu T, Noguchi CT. SATB1 family protein expressed during early erythroid differentiation modifies globin gene expression. Blood. 2005;105:3330-9.

103. Ishibashi T, Yokota T, Satoh Y, Ichii M, Sudo T, Doi Y, et al. Identification of MS4A3 as a reliable marker for early myeloid differentiation in human hematopoiesis. Biochem Biophys Res Commun. 2018;495:2338-43.

104. Kakugawa K, Kojo S, Tanaka H, Seo W, Endo TA, Kitagawa Y, et al. Essential roles of SATB1 in specifying T lymphocyte subsets. Cell Rep. 2017;19:1176-88.

105. Wei J, Shi Y, Zheng L, Zhou B, Inose H, Wang J, et al. miR-34s inhibit osteoblast proliferation and differentiation in the mouse by targeting SATB2. J Cell Biol. 2012;197:509-21.
106. Leone DP, Heavner WE, Ferenczi EA, Dobreva G, Huguenard JR, Grosschedl R, et al. Satb2 Regulates the differentiation of both callosal and subcerebral projection neurons in the developing cerebral cortex. Cereb Cortex. 2015;25:3406-19.

107. Asanoma K, Kubota K, Chakraborty D, Renaud SJ, Wake N, Fukushima K, et al. SATB homeobox proteins regulate trophoblast stem cell renewal and differentiation. J Biol Chem. 2012;287:2257-68.

108. Reya T, Morrison SJ, Clarke MF, Weissman IL. Stem cells, cancer, and cancer stem cells. Nature. 2001;414:105-11.

109. Kreso A, Dick JE. Evolution of the cancer stem cell model. Cell Stem Cell. 2014;14:275-91.

110. Choi S, Ku JL. Resistance of colorectal cancer cells to radiation and 5-FU is associated with MELK expression. Biochem Biophys Res Commun. 2011;412:207-13.

111. Elshamy WM, Duhé RJ. Overview: cellular plasticity, cancer stem cells and metastasis. Cancer Lett. 2013;341:2-8.

112. Yamashita T, Wang XW. Cancer stem cells in the development of liver cancer. J Clin Invest. 2013;123:1911-8.

113. Sun Z, Zhang C, Zou X, Jiang G, Xu Z, Li W, et al. Special ATrich sequence-binding protein-1 participates in the maintenance of breast cancer stem cells through regulation of the Notch signaling pathway and expression of Snail1 and Twist1. Mol Med Rep. 2015;11:3235-542.

114. Song G, Liu K, Yang X, Mu B, Yang J, He L, et al. SATB1 plays an oncogenic role in esophageal cancer by up-regulation of FN1 and PDGFRB. Oncotarget. 2017;8:17771-84.

115. Dragomir A, de Wit M, Johansson C, Uhlen M, Pontén F. The role of SATB2 as a diagnostic marker for tumors of colorectal origin: Results of a pathology-based clinical prospective study. Am J Clin Pathol. 2014;141:630-8.

116. Aprelikova O, Yu X, Palla J, Wei BR, John S, Yi M, et al. The role of miR-31 and its target gene SATB2 in cancer-associated fibroblasts. Cell Cycle. 2010;9:4387-98.

117. Li Y, YH Liu, YY Hu, Chen L Li, et al. Special AT-rich sequencebinding protein 2 acts as a negative regulator of stemness in colorectal cancer cells. World J Gastroenterol. 2016;22:8528-39.

118. Gong F, Sun L, Wang Z, Shi J, Li W, Wang S, et al. The BCL2 gene is regulated by a special AT-rich sequence binding protein 1 -mediated long range chromosomal interaction between the promoter and the distal element located within the $3^{\prime}$-UTR. Nucleic Acids Res. 2011;39:4640-52.

119. Yang Y, Wang Z, Sun L, Shao L, Yang N, Yu D, et al. SATB1 mediates long-range chromatin interactions: a dual regulator of anti-apoptotic BCL2 and pro-apoptotic NOXA genes. PLoS ONE. 2015;10:e139170.

120. Nagpal N, Ahmad HM, Molparia B, Kulshreshtha R. MicroRNA-191, an estrogen-responsive microRNA, functions as an oncogenic regulator in human breast cancer. Carcinogenesis. 2013;34:1889-99.

121. Chu SH, Zhou ZM, Feng DF, Ma YB. Inhibition of human glioma U251 cells growth in vitro and in vivo by hydroxyapatite nanoparticle-assisted delivery of short hairpin RNAs against SATB1. Mol Biol Rep. 2014;41:977-86.

122. Nodin B, Johannesson H, Wangefjord S, O'Connor DP, Lindquist KE, Uhlén $\mathrm{M}$, et al. Molecular correlates and prognostic significance of SATB1 expression in colorectal cancer. Diagn Pathol. 2012;7:115.

123. Laurinavicius A, Green AR, Laurinaviciene A, Smailyte G, Ostapenko V, Meskauskas R, et al. Ki67/SATB1 ratio is an independent prognostic factor of overall survival in patients with early hormone receptor-positive invasive ductal breast carcinoma. Oncotarget. 2015;6:41134-45.

124. Qi H, Fu X, Li Y, Pang X, Chen S, Zhu X, et al. SATB1 promotes epithelial-mesenchymal transition and metastasis in prostate cancer. Oncol Lett. 2017;13:2577-82. 
125. Ma J, Wu K, Zhao Z, Miao R, Xu Z. Special AT-rich sequence binding protein 1 promotes tumor growth and metastasis of esophageal squamous cell carcinoma. Tumour Biol. 2017;39:1010428317694537.

126. Wu D, Zeng L, Liu F, Zhong Q, Zhang D, Cai C, et al. Special AT-rich DNA-binding protein-1 expression is associated with liver cancer metastasis. Oncol Lett. 2016;12:4377-84.

127. Kowalczyk AE, Krazinski BE, Godlewski J, Grzegrzolka J, Kiewisz J, Kwiatkowski P, et al. SATB1 is down-regulated in clear cell renal cell carcinoma and correlates with miR-21-5p overexpression and poor prognosis. Cancer Genom Proteom. 2016;13:209-17.

128. Eberhard J, Gaber A, Wangefjord S, Nodin B, Uhlen M, Ericson Lindquist $\mathrm{K}$, et al. A cohort study of the prognostic and treatment predictive value of SATB2 expression in colorectal cancer. Br J Cancer. 2012;106:931-8.

129. Kucuksayan H, Ozes ON, Akca H. Downregulation of SATB2 is critical for induction of epithelial-to-mesenchymal transition and invasion of NSCLC cells. Lung Cancer. 2016;98:122-9.

130. Wan F, Cheng C, Wang Z, Xiao X, Zeng H, Xing S, et al. SATB1 overexpression regulates the development and progression in bladder cancer through EMT. PLOS ONE. 2015;10: e0117518.

131. Tu W, Luo M, Wang Z, Yan W, Xia Y, Deng H, et al. Upregulation of SATB1 promotes tumor growth and metastasis in liver cancer. Liver Int. 2012;32:1064-78.

132. Li QQ, Chen ZQ, Cao XX, Xu JD, Xu JW, Chen YY, et al. Involvement of $\mathrm{NF}-\mathrm{\kappa B} / \mathrm{miR}-448$ regulatory feedback loop in chemotherapy-induced epithelial-mesenchymal transition of breast cancer cells. Cell Death Differ. 2011;18:16-25.

133. Yang $\mathrm{MH}, \mathrm{Yu}$ J, Chen N, Wang XY, Liu XY, Wang S, et al. Elevated microRNA-31 expression regulates colorectal cancer progression by repressing its target gene SATB2. PLOS ONE. 2013;8:e85353.

134. Yang MH, Yu J, Jiang DM, Li WL, Wang S, Ding YQ. MicroRNA-182 targets special AT-rich sequence-binding protein 2 to promote colorectal cancer proliferation and metastasis. $\mathrm{J}$ Transl Med. 2014;12:109.

135. Gu J, Wang G, Liu H, Xiong C. SATB2 targeted by methylated miR-34c-5p suppresses proliferation and metastasis attenuating the epithelial-mesenchymal transition in colorectal cancer. Cell Prolif. 2018:51:e12455.

136. Mansour MA, Hyodo T, Akter KA, Kokuryo T, Uehara K, Nagino M, et al. SATB1 and SATB2 play opposing roles in cMyc expression and progression of colorectal cancer. Oncotarget. 2016;7:4993-5006.

137. Lee JJ, Kim M, Kim HP. Epigenetic regulation of long noncoding RNA UCA1 by SATB1 in breast cancer. BMB Rep. 2016:49:578-83.

138. Tsuji T, Ibaragi S, Hu GF. Epithelial-mesenchymal transition and cell cooperativity in metastasis. Cancer Res. 2009;69:7135-9.

139. Banyard J, Bielenberg DR. The role of EMT and MET in cancer dissemination. Connect Tissue Res. 2015;56:403-13.

140. Monteiro J, Fodde R. Cancer stemness and metastasis: therapeutic consequences and perspectives. Eur $\mathrm{J}$ Cancer. 2010;46:1198-203.

141. Jolly MK, Ware KE, Gilja S, Somarelli JA, Levine H. EMT and MET: necessary or permissive for metastasis? Mol Oncol. 2017;11:755-69.

142. Yu W, Ma Y, Ochoa AC, Shankar S, Srivastava RK. Cellular transformation of human mammary epithelial cells by SATB2. Stem Cell Res. 2017;19:139-47.

143. Alvarez JD, Yasui DH, Niida H, Joh T, Loh DY, KohwiShigematsu T. The MAR-binding protein SATB1 orchestrates temporal and spatial expression of multiple genes during T-cell development. Genes Dev. 2000;14:521-35.
144. Nixon BG, Li MO. Satb1: restraining PD1 and T cell exhaustion. Immunity. 2017;46:3-5.

145. Akimova T, Zhang T, Negorev D, Singhal S, Stadanlick J, Rao A, et al. Human lung tumor FOXP3 + Tregs upregulate four "Treg-locking" transcription factors. JCI Insight. 2017;2:94075.

146. Tesone AJ, Rutkowski MR, Brencicova E, Svoronos N, PeralesPuchalt A, Stephen TL, et al. Satb1 overexpression drives tumorpromoting activities in cancer-associated dendritic cells. Cell Rep. 2016;14:1774-86.

147. Ganesan AP, Johansson M, Ruffell B, Yagui-Beltrán A, Lau J, Jablons DM, et al. Tumor-infiltrating regulatory $\mathrm{T}$ cells inhibit endogenous cytotoxic $\mathrm{T}$ cell responses to lung adenocarcinoma. $\mathrm{J}$ Immunol. 2013;191:2009-17.

148. Fu W, Ergun A, Lu T, Hill JA, Haxhinasto S, Fassett MS, et al. A multiply redundant genetic switch "locks in" the transcriptional signature of regulatory T cells. Nat Immunol. 2012;10:972-80.

149. Grzanka J, Leveson-Gower D, Golab K, Wang XJ, MarekTrzonkowska N, Krzystyniak A, et al. FoxP3, Helios, and SATB1: roles and relationships in regulatory $\mathrm{T}$ cells. Int Immunopharmacol. 2013;16:343-7.

150. Ilarregui JM, Croci DO, Bianco GA, Toscano MA, Salatino M, Vermeulen ME, et al. Tolerogenic signals delivered by dendritic cells to $\mathrm{T}$ cells through a galectin-1-driven immunoregulatory circuit involving interleukin 27 and interleukin 10. Nat Immunol. 2009;10:981-91.

151. Toscano MA, Bianco GA, Ilarregui JM, Croci DO, Correale J, Hernandez JD, et al. Differential glycosylation of TH1, TH2 and TH-17 effector cells selectively regulates susceptibility to cell death. Nat Immunol. 2007;8:825-34.

152. Wang J, Lu ZH, Gabius HJ, Rohowsky-Kochan C, Ledeen RW, Wu G. Cross-linking of GM1 ganglioside by galectin-1 mediates regulatory $\mathrm{T}$ cell activity involving TRPC5 channel activation: possible role in suppressing experimental autoimmune encephalomyelitis. J Immunol. 2009;182:4036-45.

153. Dalotto-Moreno T, Croci DO, Cerliani JP, Martinez-Allo VC, Dergan-Dylon S, Méndez-Huergo SP, et al. Targeting galectin-1 overcomes breast cancer-associated immunosuppression and prevents metastatic disease. Cancer Res. 2013;73:1107-17.

154. Ma Y, Shurin GV, Gutkin DW, Shurin MR. Tumor associated regulatory dendritic cells. Semin Cancer Biol. 2012;22:298-306.

155. Raker VK, Domogalla MP, Steinbrink K. Tolerogenic dendritic cells for regulatory $\mathrm{T}$ cell induction in man. Front Immunol. 2015;6:569.

156. Torres-Aguilar H, Sánchez-Torres $\mathrm{C}$, Jara LJ, Blank M, Shoenfeld Y. IL-10/TGF-beta-treated dendritic cells, pulsed with insulin, specifically reduce the response to insulin of CD4+ effector/memory $\mathrm{T}$ cells from type 1 diabetic individuals. J Clin Immunol. 2010;30:659-68.

157. Agrelo R, Kishimoto H, Novatchkova M, Peraza V, Paolino M, Souabni A, et al. SATB1 collaborates with loss of p16 in cellular transformation. Oncogene. 2013;32:5492-500.

158. Lo PK, Zhang Y, Yao Y, Wolfson B, Yu J, Han SY, et al. Tumor-associated myoepithelial cells promote the invasive progression of ductal carcinoma in situ through activation of TGF $\beta$ signaling. J Biol Chem. 2017;292:11466-84.

159. Anaya J. OncoLnc: linking TCGA survival data to mRNAs, miRNAs, and lncRNAs. Peer J Comput Sci. 2016. https://doi. org/10.7717/peerj-cs.67.

160. Wang S, Wang L, Zhang Y, Liu Y, Meng F, Ma J, et al. Special AT-rich sequence-binding protein 1: a novel biomarker predicting cervical squamous cell carcinoma prognosis and lymph node metastasis. Jpn J Clin Oncol. 2015;45:812-8.

161. Hedner C, Gaber A, Korkocic D, Nodin B, Uhlén M, Kuteeva E, et al. SATB1 is an independent prognostic factor in radically resected upper gastrointestinal tract adenocarcinoma. Virchows Arch. 2014;465:649-59. 
162. Wang G, Li B, Fu Y, He M, Wang J, Shen P, et al. miR-23a suppresses proliferation of osteosarcoma cells by targeting SATB1. Tumour Biol. 2015;36:4715-21.

163. Zhang H, Qu S, Li S, Wang Y, Li Y, Wang Y, et al. Silencing SATB1 inhibits proliferation of human osteosarcoma U2OS cells. Mol Cell Biochem. 2013;378:39-45.

164. Liu SH, Zhu JW, Xu HH, Zhang GQ, Wang Y, Liu YM, et al. A novel antisense long non-coding RNA SATB2-AS1 overexpresses in osteosarcoma and increases cell proliferation and growth. Mol Cell Biochem. 2017;430:47-56.

165. Choudhary D, Clement JM, Choudhary S, Voznesensky O, Pilbeam CC, Woolbright BL, et al. SATB1 and bladder cancer: is there a functional link? Urol Oncol. 2018;3:93.e13-93.e21.

166. Guo C, Xiong D, Yao X, Gu W, Zhang H, Yang B, et al. Decreased SATB2 expression is associated with metastasis and poor prognosis in human clear cell renal cell carcinoma. Int $\mathbf{J}$ Clin Exp Pathol. 2015;8:3710-8.

167. Chen B, Xue Z, Yang G, Shi B, Yang B, Yan Y, et al. Akt-signal integration is involved in the differentiation of embryonal carcinoma cells. PLoS ONE. 2013;8:e64877.

168. Tan JA, Song J, Chen Y, Durrin LK. Phosphorylation-dependent interaction of SATB1 and PIAS1 directs SUMO-regulated caspase cleavage of SATB1. Mol Cell Biol. 2010;30:2823-36.

169. Tan JA, Sun Y, Song J, Chen Y, Krontiris TG, Durrin LK. SUMO conjugation to the matrix attachment region-binding protein, special AT-rich sequence-binding protein-1 (SATB1), targets SATB1 to promyelocytic nuclear bodies where it undergoes caspase cleavage. J Biol Chem. 2008;283:18124-34.
170. Rao H, Bai Y, Li Q, Zhuang B, Yuan Y, Liu Y et al. SATB1 down-regulation induced by oxidative stress participates in trophoblast invasion by regulating $\beta$-catenin. Biol Reprod. 2018. https://doi.org/10.1093/biolre/ioy033.

171. Gao XY, Xue XH, Ma YN, Zhang SQ. Effect of baicalein on the expression of SATB1 in human breast cancer cells. Exp Ther Med. 2015;9:1665-9.

172. Ma X, Yan W, Dai Z, Gao X, Ma Y, Xu Q, et al. Baicalein suppresses metastasis of breast cancer cells by inhibiting EMT via downregulation of SATB1 and Wnt/beta-catenin pathway. Drug Des Dev Ther. 2016;10:1419-41.

173. Reddy CN, Vyjayanti VN, Notani D, Galande S, Kotamraju S. Down-regulation of the global regulator SATB1 by statins in COLO205 colon cancer cells. Mol Med Rep. 2010;3:857-61.

174. Doi Y, Yokota T, Satoh Y, Okuzaki D, Tokunaga M, Ishibashi T, et al. Variable SATB1 levels regulate hematopoietic stem cell heterogeneity with distinct lineage fate. Cell Rep. 2018;23:322335 .

175. Tanaka Y, Sotome T, Inoue A, Mukozu T, Kuwabara T, Mikami T, et al. SATB1 conditional knockout results in Sjögren's syndrome in mice. J Immunol. 2017;199:4016-22.

176. Conejo-Garcia JR, Rutkowski MR, Cubillos-Ruiz JR. State-ofthe-art of regulatory dendritic cells in cancer. Pharmacol Ther. 2016;164:97-104.

177. Wang M, Yin SB, Matsueda L, Deng Y, Li W, Zhao J, et al. Identification of special AT-rich sequence binding protein 1 as a novel tumor antigen recognized by $\mathrm{CD} 8+\mathrm{T}$ cells: implication for cancer immunotherapy. PLOS ONE. 2013;8:e56730. 